\title{
The Portrait Machine
}

\author{
David Upton \\ King's College London \\ The Strand, London WC2R 2LS, UK \\ David.Upton@kcl.ac.uk
}

\begin{abstract}
This art project questions the way in which we relate to generative art, and also the way in which humans ascribe 'meaning' to art works made by machines. This is done via a practical experiment offering all conference participants the chance to have a portrait of themselves at no cost.
\end{abstract}

Generative art. Value. Image analysis. Interpretation. Portraiture. Psychology.

\section{INTRODUCTION}

Generative art has been defined as "any art practice where the artist uses a system, such as a set of natural language rules, a computer program, a machine, or other procedural invention, which is set into motion with some degree of autonomy, contributing to or resulting in a completed work of art". (Galanter 2003). It often raises the question 'but is it art?' - largely because the human 'artist' has little direct involvement in the final machinemade art-work.

This paper and demonstration will be a small-scale social experiment, to see how EVA attendees respond to direct involvement with a generative artistic process.

Attendees will be invited to have portraits generated for them, pavement-artist style, but by my laptop. These will combine images, live feeds, and random elements, into a composite 'interpretative' portrait in their environment at an instant in time and space.

Secondly, the project will investigate how far users create any meanings they see in an art work.

Several portraits can be generated for each sitter, who can select one, which will be given to her or him, in the form of .html or .png code emailed to them, or downloaded to a memory stick the sitter supplies.

\section{HOW DOES THE SYSTEM WORK?}

The system is based on an earlier programme written by the present author, and generates images partly by random and partly by algorithmic processes.

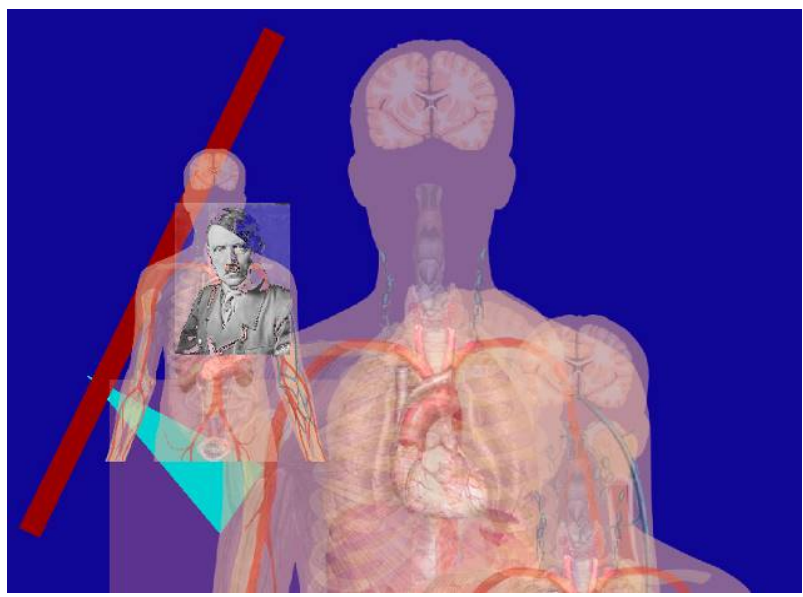

Figure 1: Image generated by an earlier programme.

The core of the system is an attempt to understand the sitter non-verbally, allowing it to select a style template, colour palette, and so on, to match and 'interpret' the sitter. Three photographs are taken, using a webcam. Two of these may be used in the portrait. The third, together with behavioural observations during the sitting process, is briefly analysed by a set of algorithms, to consider various pointers to the 'big five' personality traits. These are openness, conscientiousness, extraversion, agreeableness, and emotional stability (Gosling et al. 2003).

This is not meant as a serious psychological evaluation, but from it the system makes a guided but random selection of colours, layout, images and so on, based on its own 'reaction' to the sitter. 
A 20-minute talk/demonstration will briefly explain how the system works, and what data sources are used, and probably generate a portrait of a volunteer, whilst briefly addressing some of the theoretical questions that have been asked about generative art.

\section{BUT IS IT ART?}

The audience at EVA are assumed to be more supportive of generative art than a random selection of the population. The first part of the experiment will be to see just how often and to what extent EVA attendees engage with the process. Their views will be ascertained during the portrait process by an informal semi-structured questionnaire.

Since this will be an individual, personal, and unique portrait, I expect sitters to engage with it on several levels: as an artistic experiment, as a joke, as a personal souvenir, and also perhaps as an opportunity to acquire something that may be of monetary value one day if I become a 'hot' artist. Sitters will be given a certificate of ownership, if requested, and may even contribute to a charity as 'payment', if they wish.

It will also be instructive to see how sitters engage with the process of making the work: they will be able to instruct the machine, or to let it run randomly. They may accept the first run, or ask the machine to make several attempts before selecting one.

\section{WHEN IS A PORTRAIT SUCCESSFUL?}

Our experience with this system has been that it sometimes produces results which seem 'right' to a human user.

Classical views of art make much of a painter's ability to 'interpret', rather than just represent, the sitter. Henry James spoke of good portraits having "the quality in light of which the artist sees deep into his subject, undergoes it, absorbs it, becomes patient with it, and almost reverent, and, in short, enlarges and humanizes the technical problem" (Ron 1985).

Can an automatic system appear to interpret the character of the sitter? If so, is this because the viewer sees meaning where there was no conscious meaning inserted by the artist?

To examine this question, the system will generate three portraits each time, and the sitter will be invited to choose one that most 'captures' his or her personality. This process will be recorded by an informal semi-structured interview, designed to elicit how the sitter views the images and what significance or interpretation they appear to have. (If necessary the process can be rerun, and further images generated.) My assumption is that the more one image stands out from the others, the more likely it will be that the sitter is supplying a meaning.

Once again this will confront the valuation we put on 'instant' generative art: how do users experience its value?

\section{REFERENCES}

Galanter, P. (2003) What is generative art? Complexity theory as a context for art theory. In C. Soddu (ed.), GA2003: 6th Generative Art Conference, Milan, Italy. Error! Hyperlink reference not valid.(accessed 14 March 2017).

Gosling, S. D., Rentfrow, P. J., and Swann, W. B. (2003) A very brief measure of the Big-Five personality domains. Journal of Research in Personality, 37, pp. 504-528.

Ron, M. (1985) The art of the portrait according to James. Yale French Studies, 69, pp. 222-237. Yale University Press. http://www.jstor.org/stable/2929937 (accessed March 2017). 